\title{
Systematic Review \\ Physical Therapy Exercises for Sleep Disorders in a Rehabilitation Setting for Neurological Patients: A Systematic Review and Meta-Analysis
}

\author{
Marco Tramontano ${ }^{1, *}{ }^{-}$, Sara De Angelis ${ }^{1}$, Giovanni Galeoto ${ }^{2,3}{ }^{(}$, Maria Carmela Cucinotta ${ }^{1}$, Danilo Lisi ${ }^{4}$, \\ Riccardo Maria Botta ${ }^{5}$, Mariagrazia D'ippolito ${ }^{1}{ }^{(D}$, Giovanni Morone ${ }^{1}\left(\mathbb{D}\right.$ and Maria Gabriella Buzzi ${ }^{1}(\mathbb{D})$ \\ 1 Fondazione Santa Lucia IRCCS, 00179 Rome, Italy; s.deangelis@hsantalucia.it (S.D.A.); \\ maracucinotta3@gmail.com (M.C.C.); mg.dippolito@hsantalucia.it (M.D.); g.morone@hsantalucia.it (G.M.); \\ mg.buzzi@hsantalucia.it (M.G.B.) \\ 2 Department of Human Neurosciences, Sapienza University of Rome, 00185 Rome, Italy; \\ giovanni.galeoto@uniroma1.it \\ 3 IRCCCS Neuromed, 86077 Pozzilli, IS, Italy \\ 4 Azienda Ospedaliera Rilievo Nazionale Sant'Anna e San Sebastiano, UOC Risk Management, \\ 81100 Caserta, Italy; danilolisi@libero.it \\ 5 Azienda Ospedaliera Universitaria Mater Domini, 88100 Catanzaro, Italy; bottariccardimaria@gmail.com \\ * Correspondence: m.tramontano@hsantalucia.it; Tel.: +39-0651501420
}

\section{check for} updates

Citation: Tramontano, M.; De Angelis, S.; Galeoto, G.; Cucinotta, M.C.; Lisi, D.; Botta, R.M.; D'ippolito, M.; Morone, G.; Buzzi, M.G. Physical Therapy Exercises for Sleep Disorders in a Rehabilitation Setting for Neurological Patients: A Systematic Review and Meta-Analysis. Brain Sci. 2021, 11, 1176. https://doi.org/ 10.3390/brainsci11091176

Academic Editor: Lorenzo Priano

Received: 26 July 2021

Accepted: 2 September 2021

Published: 5 September 2021

Publisher's Note: MDPI stays neutral with regard to jurisdictional claims in published maps and institutional affiliations.

Copyright: (c) 2021 by the authors. Licensee MDPI, Basel, Switzerland. This article is an open access article distributed under the terms and conditions of the Creative Commons Attribution (CC BY) license (https:// creativecommons.org/licenses/by/ $4.0 /)$.

\begin{abstract}
Background: Sleep occupies one-third of human life and is essential for health and for emotional, physical, and cognitive well-being. Poor or insufficient sleep is associated with a wide range of dysfunctions that involve different body systems, such as the endocrine, metabolic, and immune systems, thus compromising the higher cortical functions, cognitive performance, mood, and post-physical activity recovery. The present systematic review and meta-analysis aimed to explore the effectiveness of physical therapy exercises on sleep disorders in patients with neurological disorders. Our systematic review identified 10 articles that investigated the effects of physical therapy on sleep disorders in patients with neurological disorders, 6 of which were included in the meta-analysis. Results suggest that physical therapy exercises are a safe and useful strategy for managing sleep disorders in neurorehabilitation.
\end{abstract}

Keywords: neurological diseases; sleep disorders; physical therapy; neurorehabilitation

\section{Introduction}

Sleep is a common function of living species. It occupies one-third of human life, and it is shown to be essential for health and for emotional, physical, and cognitive wellbeing [1-4]. Poor or insufficient sleep is associated with a wide range of dysfunctions that involve different body systems, such as the endocrine, metabolic, and immune systems, thus compromising the higher cortical functions, cognitive performance, mood, and postphysical activity recovery [1,4]. Sleep disturbance can affect both the duration and the quality of sleep, and when it occurs, it reduces the functionality and quality of life (QoL) of the person. Additionally, it represents a risk factor for secondary diseases and medical conditions [5]. Sleep quantity and quality can be affected by age, physical and psychological conditions, and environmental factors [4]. Several studies have shown that sleep disorders (insufficient sleep, excessive amount of perceived sleep, abnormal movements during sleep) are common among the non-motor symptoms in patients with neurological disorders [1,6-8].

Excessive daytime sleepiness, likely caused by a combination of alterations in pathophysiological mechanisms involved in the regulation of sleep/wakefulness, effects of dopaminergic drugs, and nocturnal sleep disruption, is common in patients with Parkinson's disease (PD) [7-11]. Likewise, in patients with multiple sclerosis (MS), daytime 
sleepiness represents a disturbance that contributes to fatigue and other chronic MS symptoms, highly impacting the patient's activities of daily living (ADL) [12,13].

Sleep disorders are frequently identified following traumatic brain injury (TBI); poor sleep efficiency, short sleep duration, long sleep onset, hypersomnia, and sleep-related breathing disorders have been reported $[14,15]$. Sleep apnea, insomnia, restless legs syndrome, and daytime sleepiness are common in stroke survivors, affecting not only the ADL and QoL of both patients and caregivers but also representing a high risk of further cerebrovascular events $[6,16,17]$.

Moreover, studies have shown that the quality and quantity components of sleep can be compromised by the condition of hospitalization [18,19].

During neurorehabilitation, sleep disorders can potentially affect the recovery process, through reduced ability to engage in physical therapy activities [20-24].

In addition, there is evidence that sleep disorders and depression might lead to cognitive problems, in particular related to the learning process, with limited benefits from the use of sedatives (i.e., reduced memory and learning consolidation and recall after stroke) $[25,26]$. Impaired motor learning might also affect rehabilitation outcomes during the neurorehabilitation process as a learning mechanism fundamental to harnessing neuroplasticity [27].

Thus, it may be helpful for patients with neurological diseases to carry out an assessment of the overall sleep pattern and eventually to provide appropriate management and better rehabilitation outcomes $[28,29]$

Although pharmacological treatment is widely used in the general population with sleep disorders, medication use in neurological patients who are undergoing rehabilitation may be problematic, because of possible adverse effects due to some sedative-hypnotic drugs $[30,31]$

Among non-pharmacological treatments, physical exercise has been suggested as an activity that may improve sleep disorders [32]. Studies in healthy participants have shown that physical exercise may improve both the quality and the quantity of sleep [32-34]. Furthermore, physical therapy may be considered a powerful non-pharmacological intervention for sleep disorders also in neurological disease, with consequent positive effects on both motor and non-motor functions and with minimal side effects [31,35-38]. Although physical therapy exercises may improve sleep disorders in neurological patients, they are often neglected in conventional neurorehabilitation programs.

In light of the above findings, this systematic review and meta-analysis aims to analyze the effects of physical therapy on sleep disturbances, performed in a clinical setting, in patients with neurological disorders in order to identify specific protocols that could be included in individualized conventional neurorehabilitation programs in different clinical settings.

\section{Materials and Methods}

This systematic review was performed in accordance with Preferred Reporting Items for Systematic Reviews and Meta-Analyses (PRISMA) statement [39] and the Cochrane Handbook for Systematic Reviews of Interventions [40]. The study's protocol was registered on the website of the PROSPERO International prospective register of systematic reviews (registration number CRD42021250760).

\subsection{Search Strategy and Eligibility Criteria}

Electronic databases searched in April 2021 were MEDLINE (PubMed) and Physiotherapy Evidence Database (PEDro). The search terms used were (sleep disorder*) AND (rehabilitation) AND (physical therapy modalities). The search terms were modified for each database, and appropriate subheadings were used for each database searched (for details, see Appendix A). The combination of search terms was defined using the population, intervention, comparison, and outcome (PICO) model. The population was limited to neurological patients; interventions included all the supervised physical rehabilita- 
tive protocols, manual therapy, and robotic rehabilitation; the comparison was evaluated considering no intervention, unsupervised home-based exercises, standard medical care, and other types of therapies/protocols different from the supervised physical one; and outcomes included any changes shown by the patients in sleep disorders, assessed instrumentally and/or clinically. Both studies that considered changes in sleep disorders as a primary outcome and studies that investigated changes in sleep quality and quantity as a secondary outcome were included in the present review.

Controlled and non-controlled clinical trials (i.e., randomized and non-randomized trials), retrospective studies, case reports, case series, and observational studies were included. No restrictions related to publication date, sex, and country were applied. Studies with a published full text in English or Italian were considered eligible.

Reviews, studies based on pharmacological treatments, and studies that included patients without neurological diseases were excluded.

\subsection{Study Selection and Data Collection Process}

Duplicate records were identified and removed using EndNOTE software. Study eligibility assessment and the data extraction process were carried out by two independent co-authors (SDA and MCC). In the case of any disagreement, the opinion of a third author (MT) was used to reach an agreement. The first selection of studies was initially conducted considering the title and abstract; afterward, full-text articles were examined.

The summary of results was reported following the Preferred Reporting Items for Systematic Reviews and Meta-Analyses (PRISMA) statement [39]. Two authors (DL and $\mathrm{RMB}$ ) independently extracted the following relevant features of the included studies: name of the first author and publication year, study type, participants, rehabilitative intervention, and outcome measures.

\subsection{Risk of Bias}

Following the instructions in the Cochrane Handbook for Systematic Reviews of Interventions, the risk of bias was assessed using six criteria that were individually rated for each study. In this context, selection bias, performance bias, detection bias, and attrition and reporting bias were considered by the reviewer and assessed using the PEDro score.

The risk of bias was assessed using the Cochrane risk of bias [41] for the controlled trials and using a modified version of the Newcastle-Ottawa Scale (NOS) [42] for the observational studies. The assessment was performed by two authors (SDA and MCC); discrepancies were resolved by consensus with a third reviewer (MT). The modified NOS ranges from 0 to 7 . In both scales, the higher is the score, the better is the methodological quality.

\subsection{Data Synthesis}

Data concerning qualitative synthesis were reported in a descriptive way by using means, DS, percentages, and ranges.

Quantitative analysis was conducted by comparing the outcomes used in the included studies. The studies' follow-up results were also considered and pooled.

When available, data for continuous variables were reported as mean differences (MDs), along with their 95\% confidence intervals (CIs), while dichotomous outcomes were reported as relative risks (RRs), along with their $95 \%$ CIs. In the case of missing data, the authors of the studies were contacted for further information.

A meta-analysis of either dichotomous outcomes or continuous outcomes was carried out whenever possible; when a meta-analysis was not possible, results were presented using summary and descriptive statistics. Meta-analyses were carried out using Review Manager (version 5.2.6, Cochrane Collaboration, Oxford, England), and the $p$-value was considered statistically significant at $<0.05$. 


\section{Results}

Electronic searches identified 1020 studies. Titles and abstracts were examined according to eligibility criteria. The full texts of the articles were read to determine the eligibility. Comparison of the retrieved titles identified 20 duplicates, which were excluded. The result consisted of 1000 articles eligible for inclusion. After a full-text analysis, 990 did not match the inclusion criteria, and 10 studies were included in the present systematic review, as reported in Figure 1.

PRISMA 2009 Flow Diagram
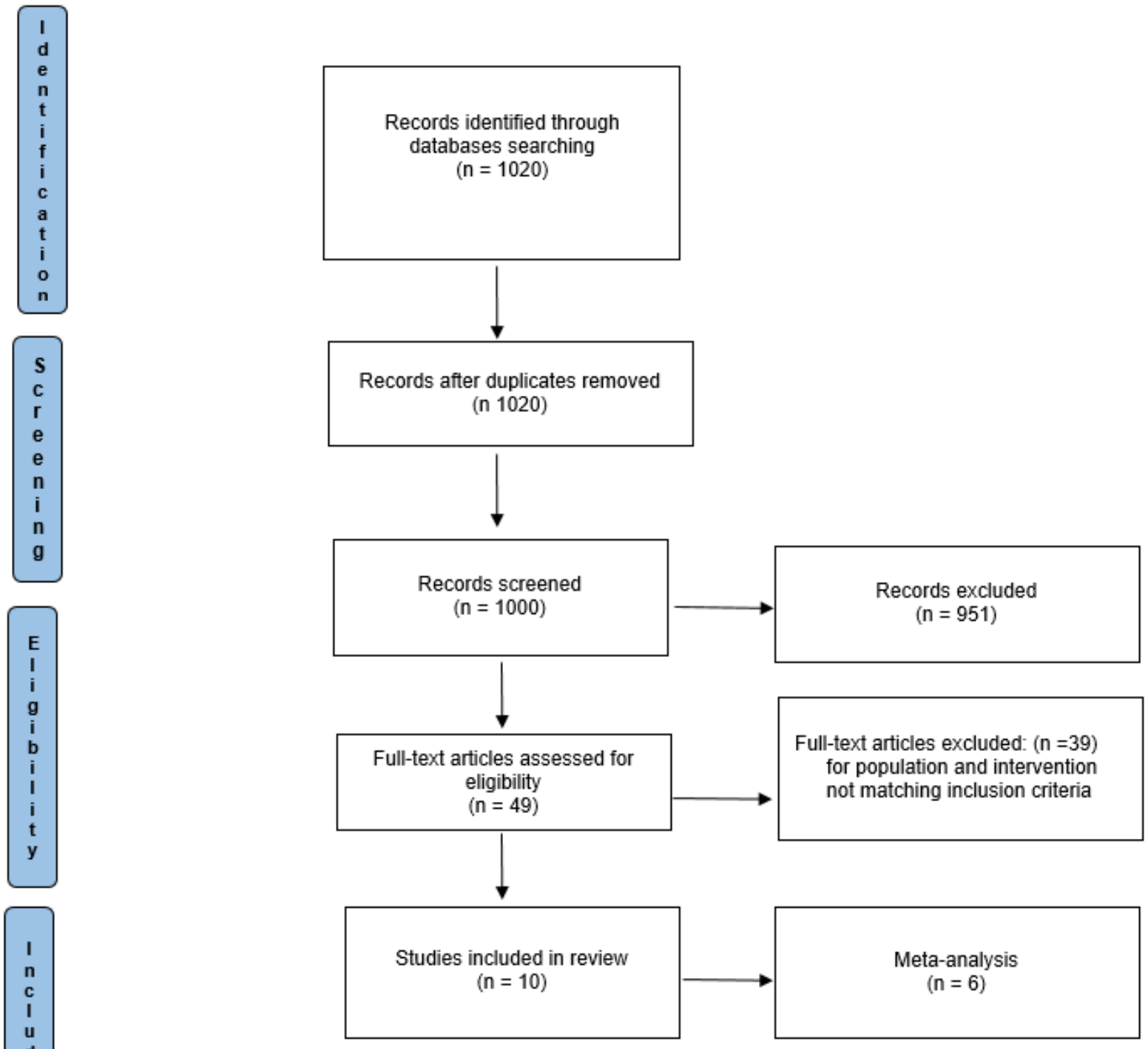

Figure 1. PRISMA flow diagram.

Table 1 presents a narrative summary of results including studies with their associated characteristics and patient features. In particular, the following data are reported: first author's name, publication year, study type, participants, intervention, intervention duration, and outcome measures. 
Table 1. Included studies according to the PICO strategy.

\begin{tabular}{|c|c|c|c|c|c|c|}
\hline Author, Year & Study Type & Population & Intervention & Comparison & Outcome Measures & Setting \\
\hline $\begin{array}{l}\text { Tidman, } 2020 \\
\text { [52] }\end{array}$ & $\begin{array}{l}\text { One-group } \\
\text { pre-test } \\
\text { and post-test }\end{array}$ & $\begin{array}{l}\text { PD }(n=22) \\
\text { Hoehn and Yahr stage between } 1 \text { and } 3 \\
\text { Mean age } 72.95 \pm 7.8 \text { years }\end{array}$ & $\begin{array}{l}\text { Community-based exercise program } \\
\text { (rotation, flexibility, } \\
\text { coordination, balance, and timing in } \\
\text { response to demonstration by class } \\
\text { instructors). } \\
\text { Duration: } 60 \text { min a day, } 3 \text { times/week, for } 8 \\
\text { weeks. }\end{array}$ & NA & - ESS & $\begin{array}{l}\text { Tertiary } \\
\text { center }\end{array}$ \\
\hline Fulk, 2020 [43] & $\mathrm{RCT}$ & $\begin{array}{l}\text { Stroke }(\mathrm{n}=408) \\
\text { Group no sleep problem }(\mathrm{NSP}): 310 \\
\text { Sleep problems with no-to-minimal impact } \\
\text { on function (SP-NMI): } 64 \\
\text { Sleep problems with moderate or quiet } \\
\text { impact on function (SP-MQBI): } 34 \\
\text { Mean age } 62.0 \pm 12.7 \text { years }\end{array}$ & $\begin{array}{l}\text { NSP: locomotor training with body weight } \\
\text { support (at } 2 \text { months post stroke). } \\
\text { SP-MQBI: late locomotor training with } \\
\text { body weight support (at } 6 \text { months post } \\
\text { stroke). } \\
\text { Duration: between } 30 \text { and } 36 \text { sessions, } 3 \\
\text { times/week for } 12 \text { to } 16 \text { weeks, each } \\
\text { session lasting } 90 \text { min. }\end{array}$ & $\begin{array}{l}\text { SP-NMI: home } \\
\text { exercise program (at } \\
2 \text { months post-stroke) } \\
\text { Duration: between } \\
30 \text { and } 36 \text { sessions, } 3 \\
\text { times/week for } 12 \text { to } \\
16 \text { weeks, each } \\
\text { session lasting } 90 \\
\text { min }\end{array}$ & $\begin{array}{l}\text { - SIS } \\
\text { - Self-reported impact } \\
\text { of sleep problems on } \\
\text { health-related quality } \\
\text { of life (questionnaire) }\end{array}$ & Hospital \\
\hline $\begin{array}{l}\text { Amara, } 2020 \\
{[44]}\end{array}$ & $\mathrm{RCT}$ & $\begin{array}{l}\text { PD }(n=55) \\
\text { Resistance training (RT): } 27 \\
\text { Sleep hygiene intervention (SHI): } 28 \\
\text { Hoehn and Yahr stages between } 2 \text { and } 3 \\
\text { Age } \geq 45 \text { years }\end{array}$ & $\begin{array}{l}\text { RT: combination of resistance training and } \\
\text { body weight functional mobility exercises } \\
\text { with limited rest intervals that we } \\
\text { previously used in PD to challenge } \\
\text { strength, power, balance, and endurance. } \\
\text { After a familiarization session, resistance } \\
\text { training volume and intensity progressed } \\
\text { during a ramp-up phase over the first } 4 \\
\text { sessions by increasing the number of sets } \\
\text { (i.e., first day, } 1 \text { set; second day, } 1 \text { set; third } \\
\text { day, } 2 \text { sets; and fourth day, } 3 \text { sets). } \\
\text { Thereafter, RT intensity/training loads } \\
\text { targeted } 10 \text { repetitions maximum (10 RM) } \\
\text { in sessions } 1 \text { and } 3 \text { each week. For session } 2 \text {, } \\
\text { resistance loads were reduced by } 30 \% \text {, } \\
\text { with greater emphasis on maximizing the } \\
\text { speed of movement during the concentric } \\
\text { phase (eccentric phase was } \\
\text { controlled/slowed) for } 12 \text { repetitions/set. } \\
\text { Duration: } 3 \text { times/week for } 16 \text { weeks. }\end{array}$ & $\begin{array}{l}\text { SHI: Participants } \\
\text { randomized to the } \\
\text { sleep hygiene } \\
\text { intervention received } \\
\text { suggestions for } \\
\text { improving sleep } \\
\text { hygiene through } \\
\text { discussion with a } \\
\text { board-certified sleep } \\
\text { medicine physician. } \\
\text { Duration: } 30-60 \text { min } \\
\text { + telephone call every } \\
4 \text { weeks to address } \\
\text { any questions about } \\
\text { sleep hygiene } \\
\text { measures }\end{array}$ & $\begin{array}{l}\text { - PSG } \\
\text { - PSQI } \\
\text { - ESS } \\
\text { - FSS } \\
\text { - PVT }\end{array}$ & $\begin{array}{l}\text { Tertiary } \\
\text { center }\end{array}$ \\
\hline
\end{tabular}


Table 1. Cont.

\begin{tabular}{|c|c|c|c|c|c|c|}
\hline Author, Year & Study Type & Population & Intervention & Comparison & Outcome Measures & Setting \\
\hline $\begin{array}{l}\text { Al-Sharman, } \\
2019 \text { [45] }\end{array}$ & $\mathrm{RCT}$ & $\begin{array}{l}\text { MS }(\mathrm{n}=40) \\
\text { Moderate-intensity aerobic } \\
\text { exercise (MAE) program }=20 \\
\text { Home exercise program }=20 \\
\text { EDSS score of } 3-5.5 \\
\text { PSQI }>5 \\
\text { Duration of disease: } 9.6 \pm 8.49 \text { (MAE); } 5.43 \\
\pm 4.2(\mathrm{HEP}) \text { Mean age: } 38.7 \pm 13 \text { years } \\
(\mathrm{MAE}) ; 31.9 \pm 10 \text { years }(\mathrm{HEP})\end{array}$ & $\begin{array}{l}\text { MAE: MAE + stretching exercises before } \\
\text { and } \\
\text { after each exercise session. } \\
\text { Duration: } 18 \text { sessions, } 3 \text { times/week for } 6 \\
\text { weeks. Each session lasted approximately } \\
50-60 \text { min }+15 \text { min before and after each } \\
\text { exercise session (stretching exercises). }\end{array}$ & $\begin{array}{l}\text { HEP: home exercise } \\
\text { program + stretching } \\
\text { exercises before and } \\
\text { after each exercise } \\
\text { session } \\
\text { Duration: } 18 \\
\text { sessions, } 3 \\
\text { times / week for } 6 \\
\text { weeks, each session } \\
\text { lasting } \\
\text { approximately } 50-60 \\
\text { min + } 15 \text { min before } \\
\text { and } \\
\text { after each exercise } \\
\text { session (stretching } \\
\text { exercises) }\end{array}$ & $\begin{array}{l}\text { - PSQI } \\
\text { - ISI } \\
\text { - Actigraphy } \\
\text { (Actigraph } \\
\text { wGT3X-BT, } \\
\text { Pensacola, FL, } \\
\text { USA) } \\
\text { - Biomarkers } \\
\text { (melatonin, cortisol) }\end{array}$ & Hospital \\
\hline $\begin{array}{l}\text { Sadeghi } \\
\text { Bahmani, } 2019 \\
{[46]}\end{array}$ & $\mathrm{RCT}$ & $\begin{array}{l}\text { MS }(\mathrm{n}=71) \\
\text { Endurance training }(\mathrm{ET}): 24 \\
\text { Coordinative training }(\mathrm{CT}): 26 \\
\text { Active control condition }(\mathrm{ACC}): 21 \\
\text { Female; EDSS < 6; age range 18-65 years }\end{array}$ & $\begin{array}{l}\text { ET: endurance training } 25-35 \text { min on a } \\
\text { treadmill, exercise bicycle, or } \\
\text { walking/jogging with individual pauses of } \\
1-2 \text { min, followed by } 5 \text { min of cooling } \\
\text { down. } \\
\text { CT: } 30-45 \text { min/session. } 5 \text { min of warming } \\
\text { up, exercises focused on CT as balancing on } \\
\text { a small bar, mirroring and imitating } \\
\text { instructors' movements, balancing balls, } \\
\text { mirroring participants' bouncing with balls } \\
\text { of different sizes, surfaces, and weights, } \\
\text { "football-tennis," balancing with closed } \\
\text { eyes on a rope on the floor, and similar } \\
\text { exercises. } \\
\text { Duration: } 3 \text { times/week for about } 45-60 \\
\text { min for } 8 \text { consecutive weeks. }\end{array}$ & $\begin{array}{l}\text { ACC: active control } \\
\text { condition met } 3 \\
\text { times/week for } \\
30-45 \text { min/session at } \\
\text { the hospital center to } \\
\text { ensure that } \\
\text { frequency, duration, } \\
\text { and the degree of } \\
\text { social contacts of the } \\
\text { control condition } \\
\text { were identical to the } \\
\text { endurance and } \\
\text { resistance training } \\
\text { conditions } \\
\text { Duration: } 3 \\
\text { times/week for } \\
\text { about } 45-60 \text { min for } \\
8 \text { consecutive weeks }\end{array}$ & $\begin{array}{l}\text { - ISI } \\
\text { - BDI-FS } \\
\text { - FSS }\end{array}$ & $\begin{array}{l}\text { University } \\
\text { hospital }\end{array}$ \\
\hline
\end{tabular}


Table 1. Cont.

\begin{tabular}{|c|c|c|c|c|c|c|}
\hline Author, Year & Study Type & Population & Intervention & Comparison & Outcome Measures & Setting \\
\hline $\begin{array}{l}\text { Colledge, } 2017 \\
\text { [51] }\end{array}$ & $\begin{array}{l}\text { Exploratory } \\
\text { pre-post-test } \\
\text { investigation } \\
\text { with a 6-month } \\
\text { follow-up }\end{array}$ & $\begin{array}{l}\text { Stroke }(\mathrm{n}=48) \\
\text { Aneurysmal subarachnoid hemorrhage } \\
(\text { aSAH }) \\
\text { Mean age } 58.5 \pm 12.4 \text { years }\end{array}$ & $\begin{array}{l}\text { Individualized exercise program with a } \\
\text { total energy expenditure of } 17.5 \\
\mathrm{kcal} / \mathrm{kg} \text { /week for each participant } \\
\text { (walking techniques, explained flexibility } \\
\text { and motor skill learning tasks, and taught } \\
\text { behavioral skills). } \\
\text { Duration: } 3-5 \text { times/week over } 12 \text { weeks. } \\
\text { Single exercise sessions lasted between } 30 \\
\text { and } 45 \text { min. }\end{array}$ & NA & $\begin{array}{l}\text { Night sleep EEG } \\
\text { (Fp2-A1; } \\
\text { electro-oculogram; } \\
\text { electromyogram; } \\
\text { SOMNOwatchTM, } \\
\text { Randersacker, } \\
\text { Germany) }\end{array}$ & $\begin{array}{l}\text { University } \\
\text { hospital }\end{array}$ \\
\hline $\begin{array}{l}\text { Silva-Batista, } \\
2017 \text { [47] }\end{array}$ & $\mathrm{RCT}$ & $\begin{array}{l}\text { PD }(\mathrm{n}=22) \\
\text { Resistance training (RT): } 11 \\
\text { No exercises (NE): } 11 \\
\text { Hoehn and Yahr stage between } 2 \text { and } 3 \\
\text { Not presenting diagnosis for insomnia } \\
\text { Age range } 64-75 \text { years }\end{array}$ & $\begin{array}{l}\text { RT: } 5 \text { resistance exercises (leg-press, } \\
\text { latissimus dorsi pull-down, ankle plantar } \\
\text { flexion, chest-press, and half-squat), twice a } \\
\text { week. Warm-up on a cycle ergometer } \\
\text { ( } 20-40 \mathrm{rpm} \text { ). A linear periodization in } \\
\text { which the training load progressed from } \\
\text { high-volume, low-intensity to low-volume, } \\
\text { high-intensity loads over } 12 \text { weeks was } \\
\text { implemented in an attempt to maximize } \\
\text { training adaptations. An interval of } 2 \text { min } \\
\text { was allowed between exercises and sets. } \\
\text { Duration: } 24 \text { sessions, } 2 \text { times / week for } 3 \\
\text { months, each session lasting } 50 \text { min. }\end{array}$ & $\begin{array}{l}\text { NE: no exercise } \\
\text { training activities }\end{array}$ & $\begin{array}{l}\text { - PSQI } \\
\text { - Knee extensor peak } \\
\text { torque (isokinetic } \\
\text { dynamometer Biodex } \\
\text { System 3; Biodex } \\
\text { Medical Systems, } \\
\text { Shirley, NY, USA) }\end{array}$ & $\begin{array}{l}\text { Tertiary } \\
\text { center }\end{array}$ \\
\hline $\begin{array}{l}\text { Nascimento, } \\
2014 \text { [49] }\end{array}$ & $\begin{array}{l}\text { No randomized } \\
\text { controlled trial }\end{array}$ & $\begin{array}{l}\text { PD }(n=34) \\
\text { Multimodal exercise program (MEP): } 17 \\
\text { Standard medical care }(\text { SMC): } 17 \\
\text { Hoehn and Yahr stages } 1 \text { through } 3 \\
\text { Mean age } 67.05 \text { years }\end{array}$ & $\begin{array}{l}\text { G1: multimodal exercise program to } \\
\text { stimulate aerobic metabolism: warm-up, } \\
\text { muscular resistance, balance and motor } \\
\text { coordination, and aerobic fitness. } \\
\text { Duration: } 1 \text { session/week for } 6 \text { months, } \\
\text { each session lasting } 60 \text { min }\end{array}$ & $\begin{array}{l}\text { SMC: standard } \\
\text { medical care routine }\end{array}$ & $\begin{array}{l}\text { - PIAQ } \\
\text { - MSQ }\end{array}$ & $\begin{array}{l}\text { University } \\
\text { clinical center }\end{array}$ \\
\hline
\end{tabular}


Table 1. Cont.

\begin{tabular}{|c|c|c|c|c|c|c|}
\hline Author, Year & Study Type & Population & Intervention & Comparison & Outcome Measures & Setting \\
\hline Wang, 2010 [48] & $\mathrm{RCT}$ & $\begin{array}{l}\text { Stroke }(\mathrm{n}=34) \\
\text { Tai chi }(\mathrm{TC}): 17 \\
\text { Non-resistance training }(\mathrm{NRT}): 17 \\
\text { Intracerebral hemorrhage, subarachnoid } \\
\text { hemorrhage, or cerebral infarction } \\
\text { Age } \geq 50 \text { years }\end{array}$ & $\begin{array}{l}\text { TC: tai chi program based on classical Yang } \\
\text { style (warm-up, practice, cool down). } \\
\text { Duration: once a week for } 12 \text { weeks, each } \\
\text { session lasting } 50 \text { min. }\end{array}$ & $\begin{array}{l}\text { NRT: rehabilitation } \\
\text { program } \\
\text { Non-resistance } \\
\text { training (such as } \\
\text { walking and/or } \\
\text { standing and } \\
\text { resistance training } \\
\text { using exercise } \\
\text { machines and } \\
\text { Thera-Band Tubing } \\
\text { Duration: once a } \\
\text { week for } 12 \text { weeks, } \\
\text { each session lasting } \\
80 \text { min }\end{array}$ & $\begin{array}{l}\text { - 60-item GHQ } \\
\text { - PSQI }\end{array}$ & Hospital \\
\hline $\begin{array}{l}\text { De Mello, } 2002 \\
\text { [50] }\end{array}$ & $\begin{array}{l}\text { No controlled } \\
\text { trial }\end{array}$ & $\begin{array}{l}\mathrm{SCI}(\mathrm{n}=13) \\
\text { Males; spinal cord injury between } \mathrm{T} 7 \text { and } \\
\mathrm{T} 12 \text { and total injury to the upper } \\
\text { motoneurons } \\
\text { Clinically stable } \\
\text { Mean age } 31.6 \pm 8.3 \text { years }\end{array}$ & $\begin{array}{l}\text { Aerobic physical exercise: The protocol of } \\
\text { the maximum effort test consisted of a } 2 \\
\text { min warm-up with a load of } 25 \text { watts in } 5 \\
\text { watts } / \text { min load increments until } \\
\text { exhaustion, with } 3 \text { min of active recovery at } \\
\text { a load of } 25 \text { watts. The mean rotation speed } \\
\text { was } 70 \pm 80 \text { rpm. } \\
\text { Duration: } 45 \text { days of consecutive sessions, } 3 \\
\text { times/week, each session lasting a mean of } \\
30 \text { min. }\end{array}$ & & $\begin{array}{l}\text { - PSG } \\
\text { (Oxford/Medilog } 8 \\
\text { channels) } \\
\text { ( } 3 \text { EEG channels, } 2 \\
\text { EOG channels, and } 3 \\
\text { EMG channels) }\end{array}$ & $\begin{array}{l}\text { Clinical } \\
\text { center }\end{array}$ \\
\hline
\end{tabular}

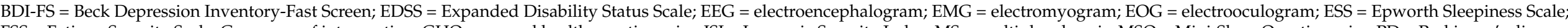

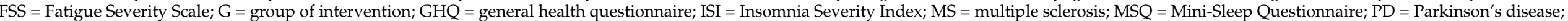

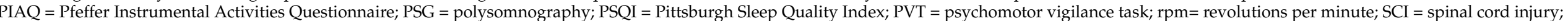
SIS = Stroke Impact Scale. 
The included studies were all published in English and were conducted in different countries: three studies came from the United States, three came from Brazil, and Japan, Iran, Jordan, and Switzerland contributed to this review with one study each. Of the five investigated neurological diseases, four studies included patients with a diagnosis of PD, three studies included patients with stroke, two studies involved patients with a diagnosis of multiple sclerosis (MS), and one study included patients with spinal cord injury (SCI) between T7 and T12; no studies regarding patients with TBI were found.

In addition, 747 patients with neurological diseases and sleep disturbance were included in the review, of whom 490 had a stroke diagnosis, 133 had a clinical diagnosis of PD, 111 were persons with MS, and 13 were patients with SCI between T7 and T12.

Among the 10 included studies, 6 studies were randomized controlled trials (RCTs) [43-48] and the other 4 studies were a non-randomized controlled trial [49], a non-controlled trial [50], an exploratory pre-post-test investigation [51], and a one-group pre-test and post-test [52].

The modified NOS scale was used to assess the quality of non-RCTs. The NOS scale of the included studies ranged between 5 to 6 , with a mean score of 5.4 points out of 7 (Table 2). None of the included studies reached the maximum score. The Cochrane risk of bias [41] was used for the RCTs (Figure 2).

Table 2. Modified NOS scale scores of the included studies.

\begin{tabular}{|c|c|c|c|c|c|}
\hline Author, Year & Study Type & Selection & $\begin{array}{l}\text { Treatment } \\
\text { Protocol }\end{array}$ & Outcome(s) & Total (0 to 7) \\
\hline Tidman, 2020 [52] & $\begin{array}{l}\text { One-group pre-test } \\
\text { and post-test }\end{array}$ & * & $* *$ & $* * *$ & $6 / 7$ \\
\hline Fulk, 2020 [43] & $\begin{array}{l}\text { Cross-sectional secondary analysis of } \\
\text { longitudinal data }\end{array}$ & * & $*$ & $* * *$ & $5 / 7$ \\
\hline Colledge, 2017 [51] & $\begin{array}{l}\text { Exploratory pre-post-test } \\
\text { investigation with a 6-month } \\
\text { follow-up }\end{array}$ & $*$ & * & $* * *$ & $5 / 7$ \\
\hline De Mello, 2002 [50] & No controlled trial & & $* *$ & $* * *$ & $5 / 7$ \\
\hline Nascimento, 2014 [49] & No controlled trial & $* *$ & $*$ & $* * *$ & $6 / 7$ \\
\hline \multicolumn{6}{|c|}{$\begin{array}{l}\text { The primary aim of the included studies was to evaluate the effect of a physical } \\
\text { therapy intervention on sleep disorders in patients with neurological diseases. } \\
\text { All the included studies carried out a supervised physical therapy intervention. Dif- } \\
\text { ferent types of protocols in terms of proposed exercises and duration were performed. } \\
\text { Summarizing the data, the physical therapy interventions lasted between } 6 \text { weeks and } \\
3 \text { months and with one to five sessions per week. } \\
\text { Concerning the outcomes, either instrumental or clinical assessments were performed } \\
\text { to evaluate the sleep quality and quantity. The instrumental assessments consisted of } \\
\text { polysomnography, electroencephalogram (EEG), electromyogram (EMG), electrooculogram } \\
\text { (EOG), and actigraphy. Clinical scales, tests, and questionnaires were used to clinically } \\
\text { assess sleep disorders and to investigate the patients' self-assessment of sleep quality. All } \\
\text { the outcomes are displayed in Table 1. }\end{array}$} \\
\hline
\end{tabular}



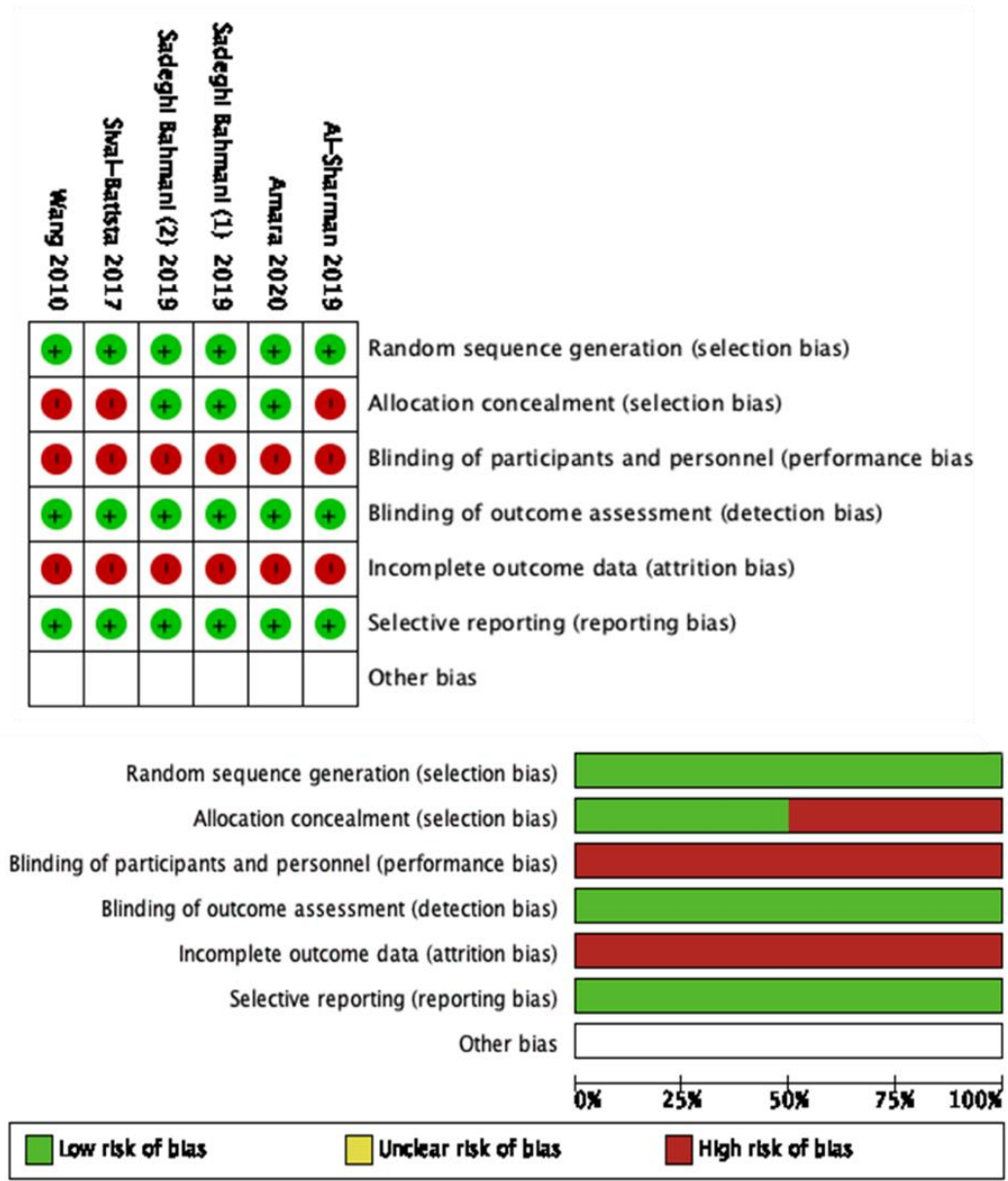

Figure 2. Cochrane risk of bias of the included studies.

\subsection{Meta-Analysis}

Quantitative analysis was carried out by comparing outcomes and follow-ups. This pool was based on comparable outcomes, and comparable times of follow-up allowed consideration of six studies in the meta-analysis (Figure 2). A description of the experimental protocol and control therapy is given in Table 1.

These six studies are as follows.

\subsubsection{Comparison Assessed with the Pittsburgh Sleep Quality Index (PSQI)}

The studies by Al-Sharman et al. [45], Amara et al. [44], Silvia- Batista et al. [47], and Wang et al. [48] were considered. Meta-analysis revealed statistically significant results $(p<0.00001)$ in favor of the experimental group compared to the control group (mean difference $=-2.57,95 \%$ confidence interval $(\mathrm{CI})=-3.31,-1.81$ ) (Figure 2).

Al-Sharman et al. [45] compared the effects of a moderate-intensity aerobic exercise program (MAE) with a home exercise program (HEP) in individuals with MS. Both the interventions were conducted for 18 sessions, three times a week for 6 weeks, and each session lasted approximately 50-60 $\mathrm{min}+15 \mathrm{~min}$ of stretching exercises before and after each exercise session. In Amara et al. [44], the effects of a resistance training (RT) intervention lasting three times a week for 16 weeks were compared with a sleep hygiene intervention (SHI) of a duration of 30-60 min + a telephone call every 4 weeks in patients with PD. Silvia-Batista et al. [47] compared an RT intervention of 24 sessions, two times per week for 3 months with a no-exercise intervention in PD. Wang et al. [48] compared the effect of a rehabilitation program based on physical exercises with a tai chi program in patients with stroke. Both the interventions were carried out once a week for 12 weeks. 


\subsubsection{Comparison Assessed with the Fatigue Severity Scale (FSS)}

The studies by Amara et al. [44] and Sadeghi Bahmani et al. [46] were considered. Meta-analysis revealed statistically significant results $(p=0.06$; mean difference $=-3.97$, $95 \%$ confidence interval $(\mathrm{CI})=-8.18,-0.25)$ (Figure 2 ).

Amara et al. [44] compared the effects of the RT intervention lasting three times a week for 16 weeks, with an SHI of a duration of 30-60 min + a telephone call every 4 weeks in patients with PD. In Sadeghi Bahmani et al. [46], an endurance training (ET) intervention and a coordinative training (CT) intervention were compared with an active control condition (ACC) in patients with MS. The three interventions were carried out three times a week for about $45-60$ min for 8 consecutive weeks.

\subsubsection{Comparison Assessed with the Insomnia Severity Index (ISI)}

The studies by Amara et al. [44] and Sadeghi Bahmani et al. [46] were considered. Meta-analysis revealed statistically significant results $(p=0.06$; mean difference $=-1.78$, $95 \%$ confidence interval $(\mathrm{CI})=-3.61,-0.04)$ (Figure 2 ).

Amara et al. [44] compared the effects of the RT intervention lasting three times a week for 16 weeks with the SHI of a duration of 30-60 min + a telephone call every 4 weeks in patients with PD. In Sadeghi Bahmani et al. [46], the ET intervention and the $\mathrm{CT}$ intervention were compared with an ACC in patients with MS. The three interventions were carried out three times a week for about $45-60$ min for 8 consecutive weeks

\subsubsection{Comparison Assessed with Wake after Sleep Onset (WASO) Minutes}

The studies by Amara et al. [44] and Al-Sharman et al. [45] were considered. Metaanalysis revealed statistically significant results $(p=0.0002$; mean difference $=-46.70,95 \%$ confidence interval $(\mathrm{CI})=-70.85,-22.55)$ (Figure 2).

In Amara et al. [44], the effects of the RT intervention lasting three times a week for 16 weeks were compared with the SHI of a duration of 30-60 min + a telephone call every 4 weeks in patients with PD. Al-Sharman et al. [45] compared the effects of an MAE with an HEP in individuals with MS. Both the interventions were conducted for 18 sessions, three times a week for 6 weeks, and each session lasted approximately 50-60 min $+15 \mathrm{~min}$ of stretching exercises before and after each exercise session.

\subsubsection{Comparison Assessed with Sleep Efficiency}

The studies by Amara et al. [44] and Al-Sharman et al. [45] were considered. Metaanalysis revealed statistically significant results $(p=0.0008$; mean difference $=8.80,95 \%$ confidence interval $(\mathrm{CI})=3.66,13.94$ ) (Figure 2).

Amara et al. [44] compared the effects of the RT intervention lasting three times a week for 16 weeks with the SHI of a duration of 30-60 min + a telephone call every 4 weeks in patients with PD. Al-Sharman et al. [45] compared the effects of an MAE with an HEP in individuals with MS. Both the interventions were conducted for 18 sessions, three times a week for 6 weeks, and each session lasted approximately 50-60 min +15 min of stretching exercises before and after each exercise session.

\subsubsection{Comparison Assessed with the Total Sleep Time (TST) Minutes}

The studies by Amara et al. [44] and Al-Sharman et al. [45] were considered. Metaanalysis revealed statistically significant results $(p=0.002$; mean difference $=42.50,95 \%$ confidence interval $(\mathrm{CI})=15.38-69.63)$.

Amara et al. [44] compared the effects of the RT intervention lasting three times a week for 16 weeks with the SHI of a duration of 30-60 min + a telephone call every 4 weeks in patients with PD. Al-Sharman et al. [45] compared the effects of an MAE with an HEP in individuals with MS. Both the interventions were conducted for 18 sessions, three times a week for 6 weeks, and each session lasted approximately 50-60 min +15 min of stretching exercises before and after each exercise session. 
Figure 3 Show the results of the meta-analysis carried out on six studies by comparing different outcomes and follow-ups. This pool was based on comparable outcomes and comparable times of follow-up. The mean, standard deviation (SD), total number of participants, and data for continuous variables were reported as the mean difference, along with their $95 \%$ confidence intervals (CIs) for each study. The risk-of-bias summary for RCTs was reported for each of the six included randomized controlled trials. Scores from the Cochrane Assessment of Bias were reported for each clinical scale: a: PSQI; $b$ : FSS; c: Insomnia; d: WASO; e: Sleep Efficiency; f: Total Sleep Time; experimental arm: supervised physical therapy; control arm: unsupervised exercises; no physical therapy; standard medical care; and other types of therapies/protocols different from the supervised physical one.

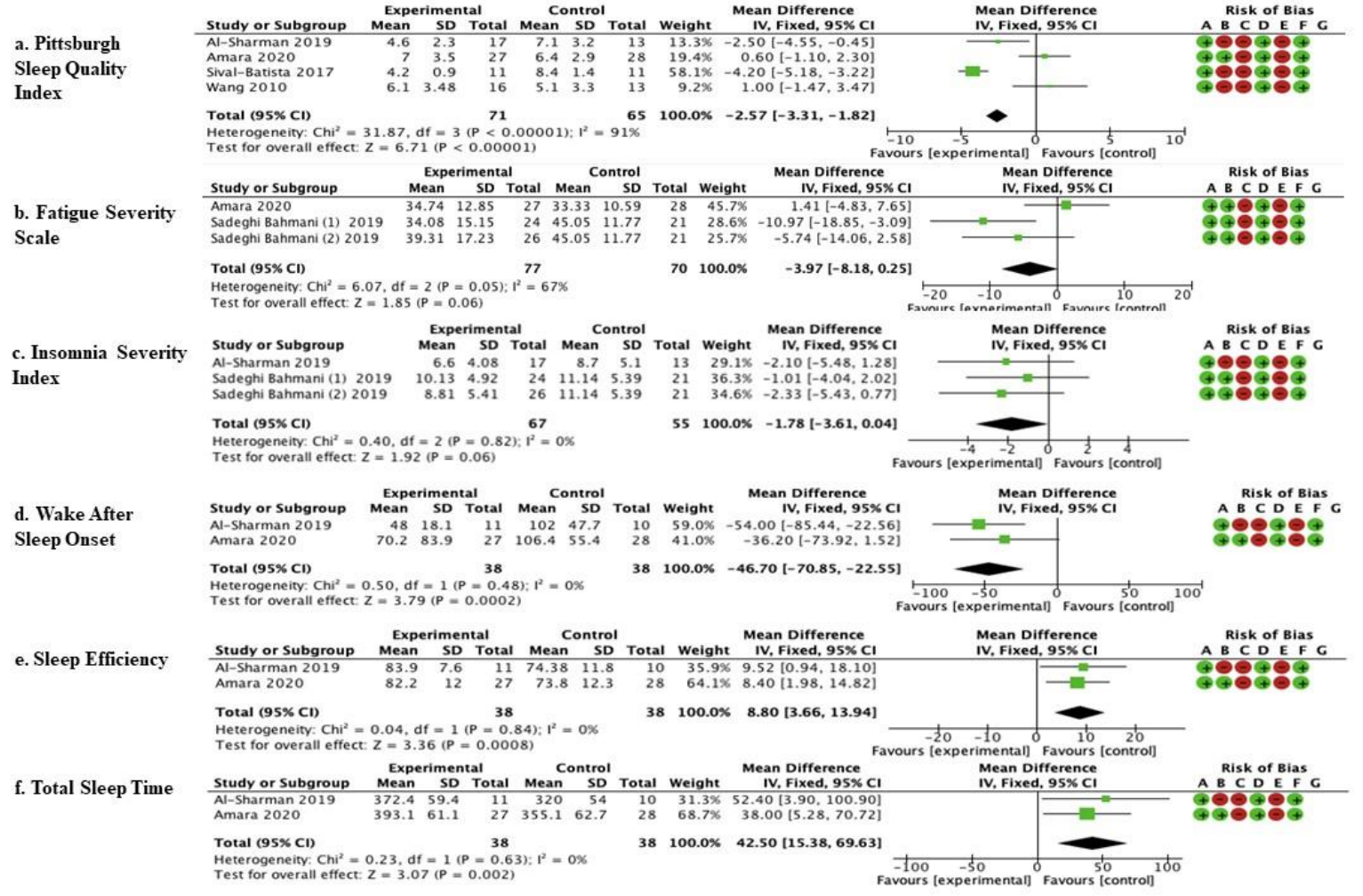

Figure 3. Comparison of physical therapy vs. comparison therapy assessed with clinical scales. high risk of bias.

\section{Discussion}

The present systematic review and meta-analysis was performed to analyze the role of physical therapy performed in a clinical setting in the improvement of sleep disturbances in neurological patients in order to identify specific protocols that could be included in individualized neurorehabilitation programs.

Results suggest that physical therapy exercises could represent a beneficial interventional for improving sleep disorders in neurological patients. However, due to the relatively few studies and the heterogeneity of the interventions, it is difficult to generalize the results. Moreover, protocols differ in duration, intensity, and required tasks.

Most of the included studies explore the effects of physical therapy on sleep disorders in patients with PD $[44,47,49,52]$, showing positive results. Specifically, multimodal physical therapy programs that stimulate aerobic metabolism and muscle endurance seem to be useful in improving sleep quality assessed by PSQI and the Mini-Sleep Questionnaire (MSQ), in addition to enhancing the sleep efficiency objectively measured with polysomnography $[44,47,48]$. Moreover, a decrease in the use of drugs promoting sleep 
was observed in patients following a physical therapy program, supporting physical exercises as a valid alternative in the non-pharmacological treatment of sleep disorders in patients with PD [44]. Interestingly, Amara et al. [44] highlighted how even an intervention based on sleep hygiene can lead to an improvement in the sleep quality assessed by the PSQI.

Although the PSQI is a subjective tool that can be conditioned by a placebo effect [53], the results shown by Amara et al. [44] leave open the possibility of linking a physical therapy program with discussion time with a board-certified sleep medicine physician to provide patients with suggestions for improving sleep hygiene. Further studies could investigate the effectiveness of this combined approach, and furthermore, they could identify the possible role of the physiotherapist in sleep hygiene programs.

Tidman et al. [52] showed an improved willingness to participate in social situations, perceived improvements in flexibility, and perceptions of improved daytime sleepiness in PD patients who performed a supervised physical exercise program, but no significant improvements were found in the sleep quality. These can lead to better adherence and responsiveness of the patient to the rehabilitation treatment, to an increased participation in ADL, and therefore to an improvement in the QoL [54].

Among the included studies, only one [45] evaluated sleep-related biomarkers (melatonin, serotonin, cortisol, highlighting that in patients with MS, aerobic training of moderate intensity leads to an increase in serotonin values. Moreover, this result, associated with the clinical and instrumental evaluation of the quality and quantity of sleep, shows a correlation between the increase in serotonin and the improvement in the quality of sleep assessed by the PSQI and the Insomnia Severity Index (ISI) after 6 weeks of physical training.

These findings are also supported by the other included study concerning MS, which showed a decrease in subjective sleep complaints after 8 weeks of physical exercise programs [46]. Although the lack of further studies prevents us from defining the efficacy of treatment in patients with MS, these results suggest that 45-60 min of exercise sessions, three times a week for a total of 18-24 sessions, may lead to an improvement of insomnia in patients with MS.

Three studies explored the effect of physical therapy treatment on post-stroke patients with sleep disorders, without clinically significant results. Specifically, they compared the effects of conventional motor rehabilitation [48], robotic-based rehabilitation [43], a home exercise program [43], and specific and individualized supervised motor training [51]. The difference between the four rehabilitation protocols and the heterogeneity of the population (different types of lesions and different times from stroke onset) do not allow us to draw conclusions.

One study [50] observed the effect of an aerobic physical exercise protocol in patients with SCI between T7 and T12 associated with periodic leg-movement-related sleep disorders. Although results identified a significant improvement in sleep quality in these patients, the lack of other studies and the small number of patients $(n=13)$ do not allow conclusions, although the data can be considered as a promising observation for further studies.

The heterogeneity of the studies makes it difficult to identify a single protocol that could be useful in improving sleep disorders in patients with neurological disorders. However, the presence of different protocols in terms of proposed exercises, settings, and populations could be considered as evidence of the great versatility and applicability of physical exercise in patients with neurological diseases associated with sleep disorders. Although physical therapy exercises for sleep disorders could be easily implemented in neurological patients, they are often neglected in conventional neurorehabilitation programs [55].

\section{Limitations of the Current Review}

Several limitations in the present review and meta-analysis are acknowledged. First was the small number of studies for each investigated pathology. Second, the methodologi- 
cal heterogeneity (e.g., study designs, outcome measures) restricted the number of studies eligible for quantitative analysis. In addition, data reporting was frequently incomplete or not always provided in a useful way to perform meta-analysis. Third, the variability of the interventions did not allow us to identify a single rehabilitative protocol that verifies the effectiveness. The internal validity of studies was also limited, and the methodological quality was low to medium, on average, as a consequence of the study designs (lack of randomization and blinding, small or uncontrolled groups). Despite the fact that sleep has a great impact on rehabilitation outcomes, there is a lack of primary research that considers sleep disturbance as a primary outcome in neurorehabilitation. Thus, we considered studies that investigated changes in sleep quality and quantity as a secondary outcome, and this aspect might have limited our findings.

\section{Conclusions}

Our review identified 10 articles that investigated the effects of physical therapy on sleep disorders in patients with neurological disorders, and 6 of them were included in a meta-analysis. Results suggest that physical therapy exercises could be a useful strategy for managing sleep disorders in neurorehabilitation. However, due to the heterogeneity of the interventions, it is difficult to generalize the results with a clinical recommendation. Future research in this area would benefit from a higher methodological quality of the study and interventions in physical therapy targeted specifically at sleep disorders.

Author Contributions: Conceptualization, M.T. and S.D.A.; methodology, M.T.; software, G.G.; formal analysis, G.G; data curation, M.C.C.; writing—original draft preparation, S.D.A. and M.T.; writing-review and editing, M.G.B., M.D., D.L., R.M.B., and G.M.; supervision, M.G.B. and G.M. All authors have read and agreed to the published version of the manuscript.

Funding: This research was partially supported by the Italian Ministry of Health (Ricerca Corrente).

Institutional Review Board Statement: Not applicable.

Informed Consent Statement: Not applicable.

Data Availability Statement: Not applicable.

Conflicts of Interest: The authors declare no conflict of interest.

\section{Appendix A}

Search Strategy in MEDLINE (PubMed)

(((sleep disorder*) AND (rehabilitation)) AND (physical therapy modalities) Search Strategy in PEDro

- Sleep disorder* AND physical therapy

- Sleep disorder* AND rehabilitation

- Sleep disorder* AND physiotherapy

Key Words

"sleep disorders"

"rehabilitation"

"“"physical therapy modalities"

"neurological diseases"

\section{References}

1. Pavlova, M.K.; Latreille, V. Sleep Disorders. Am. J. Med. 2019, 132, 292-299. [CrossRef]

2. Nissen, C.; Piosczyk, H.; Holz, J.; Maier, J.G.; Frase, L.; Sterr, A.; Riemann, D.; Feige, B. Sleep is more than rest for plasticity in the human cortex. Sleep 2021, 44, zsaa216. [CrossRef] [PubMed]

3. Tempesta, D.; Socci, V.; De Gennaro, L.; Ferrara, M. Sleep and emotional processing. Sleep Med. Rev. 2018, 40, 183-195. [CrossRef]

4. Troynikov, O.; Watson, C.G.; Nawaz, N. Sleep environments and sleep physiology: A review. J. Therm Biol. 2018, 78, 192-203. [CrossRef]

5. Dyken, M.E.; Afifi, A.K.; Lin-Dyken, D.C. Sleep-related problems in neurologic diseases. Chest 2012, 141, 528-544. [CrossRef] 
6. Pasic, Z.; Smajlovic, D.; Dostovic, Z.; Kojic, B.; Selmanovic, S. Incidence and types of sleep disorders in patients with stroke. Med. Arh. 2011, 65, 225-227. [CrossRef] [PubMed]

7. Shen, Y.; Huang, J.Y.; Li, J.; Liu, C.F. Excessive Daytime Sleepiness in Parkinson's Disease: Clinical Implications and Management. Chin. Med. J. 2018, 131, 974-981. [CrossRef] [PubMed]

8. Anderson, K. Sleep disturbance and neurological disease. Clin. Med. 2011, 11, 271-274.

9. Knie, B.; Mitra, M.T.; Logishetty, K.; Chaudhuri, K.R. Excessive daytime sleepiness in patients with Parkinson's disease. CNS Drugs 2011, 25, 203-212. [CrossRef] [PubMed]

10. Reading, P.J. Sleep disorders in neurology. Pract Neurol. 2010, 10, 300-309. [CrossRef]

11. Bonnì, S.; Ponzo, V.; Tramontano, M.; Martino Cinnera, A.; Caltagirone, C.; Koch, G.; Peppe, A. Neurophysiological and clinical effects of blindfolded balance training (BBT) in Parkinson's disease patients: A preliminary study. Eur J. Phys. Rehabil. Med. 2019, 55, 176-182. [CrossRef]

12. Devos, H.; Alissa, N.; Lynch, S.; Sadeghi, M.; Akinwuntan, A.E.; Siengsukon, C. Real-time assessment of daytime sleepiness in drivers with multiple sclerosis. Mult. Scler. Relat. Disord. 2021, 47, 102607. [CrossRef]

13. Braley, T.J.; Boudreau, E.A. Sleep Disorders in Multiple Sclerosis. Curr. Neurol. Neurosci. Rep. 2016, 16, 50. [CrossRef]

14. Albrecht, J.S.; Wickwire, E.M. Sleep disturbances among older adults following traumatic brain injury. Int. Rev. Psychiatry 2020, 32, 31-38. [CrossRef] [PubMed]

15. Wolfe, L.F.; Sahni, A.S.; Attarian, H. Sleep disorders in traumatic brain injury. NeuroRehabilitation 2018, 43, 257-266. [CrossRef]

16. Pérez-Carbonell, L.; Bashir, S. Narrative review of sleep and stroke. J. Thorac Dis. 2020, 12 (Suppl. 2), S176-S190. [CrossRef] [PubMed]

17. Mims, K.N.; Kirsch, D. Sleep and Stroke. Sleep Med. Clin. 2016, 11, 39-51. [CrossRef] [PubMed]

18. Stewart, N.H.; Arora, V.M. Sleep in Hospitalized Older Adults. Sleep Med. Clin. 2018, 13, 127-135. [CrossRef] [PubMed]

19. Wesselius, H.M.; van den Ende, E.S.; Alsma, J.; Ter Maaten, J.C.; Schuit, S.C.E.; Stassen, P.M.; de Vries, O.J.; Kaasjager, K.H.A.H.; Haak, H.R.; van Doormaal, F.F.; et al. Onderzoeks Consortium Acute Geneeskunde" Acute Medicine Research Consortium. Quality and Quantity of Sleep and Factors Associated With Sleep Disturbance in Hospitalized Patients. JAMA Intern. Med. 2018, 178, 1201-1208. [CrossRef] [PubMed]

20. Kalmbach, D.A.; Conroy, D.A.; Falk, H.; Rao, V.; Roy, D.; Peters, M.E.; Van Meter, T.E.; Korley, F.K. Poor sleep is linked to impeded recovery from traumatic brain injury. Sleep 2018, 41, zsy147. [CrossRef]

21. Drerup, M.; Roth, A.; Kane, A.; Sullivan, A.B. Therapeutic Approaches to Insomnia and Fatigue in Patients with Multiple Sclerosis. Nat. Sci. Sleep. 2021, 13, 201-207. [CrossRef] [PubMed]

22. Fleming, M.K.; Smejka, T.; Henderson Slater, D.; van Gils, V.; Garratt, E.; Yilmaz Kara, E.; Johansen-Berg, H. Sleep Disruption After Brain Injury Is Associated With Worse Motor Outcomes and Slower Functional Recovery. Neurorehabil. Neural Repair 2020, 34, 661-671. [CrossRef] [PubMed]

23. Wiseman-Hakes, C.; Murray, B.; Moineddin, R.; Rochon, E.; Cullen, N.; Gargaro, J.; Colantonio, A. Evaluating the impact of treatment for sleep/wake disorders on recovery of cognition and communication in adults with chronic TBI. Brain Inj. 2013, 27, 1364-1376. [CrossRef] [PubMed]

24. Tassorelli, C.; Tramontano, M.; Berlangieri, M.; Schweiger, V.; D'Ippolito, M.; Palmerini, V.; Bonazza, S.; Rosa, R.; Cerbo, R.; Buzzi, M.G. Assessing and treating primary headaches and cranio-facial pain in patients undergoing rehabilitation for neurological diseases. J. Headache Pain 2017, 18, 99. [CrossRef]

25. Iddagoda, M.T.; Inderjeeth, C.A.; Chan, K.; Raymond, W.D. Post-stroke sleep disturbances and rehabilitation outcomes: A prospective cohort study. Intern. Med. J. 2020, 50, 208-213. [CrossRef]

26. Duss, S.B.; Seiler, A.; Schmidt, M.H.; Pace, M.; Adamantidis, A.; Müri, R.M.; Bassetti, C.L. The role of sleep in recovery following ischemic stroke: A review of human and animal data. Neurobiol. Sleep Circadian Rhythm. 2016, 2, 94-105. [CrossRef] [PubMed]

27. Cramer, S.C.; Sur, M.; Dobkin, B.H.; O'Brien, C.; Sanger, T.D.; Trojanowski, J.Q.; Rumsey, J.M.; Hicks, R.; Cameron, J.; Chen, D.; et al. Harnessing neuroplasticity for clinical applications. Brain 2011, 134, 1591-1609. [CrossRef] [PubMed]

28. Siengsukon, C.F.; Al-Dughmi, M.; Stevens, S. Sleep Health Promotion: Practical Information for Physical Therapists. Phys. Ther. 2017, 97, 826-836. [CrossRef]

29. Caltagirone, C.; Piras, F.; Imbriani, P. Handbook of Neurorehabilitation and Principles of Neurology. Giunti Psychom. Florence Italy. 2021.

30. Abad, V.C.; Guilleminault, C. Diagnosis and treatment of sleep disorders: A brief review for clinicians. Dialogues Clin. Neurosci. 2003, 5, 371-388. [CrossRef]

31. Larson, E.B. Sleep Disorders in Neurorehabilitation. Sleep Med. Clin. 2012, 7, 587-595. [CrossRef]

32. Kredlow, M.A.; Capozzoli, M.C.; Hearon, B.A.; Calkins, A.W.; Otto, M.W. The effects of physical activity on sleep: A meta-analytic review. J. Behav. Med. 2015, 38, 427-449. [CrossRef] [PubMed]

33. Uchida, S.; Shioda, K.; Morita, Y.; Kubota, C.; Ganeko, M.; Takeda, N. Exercise effects on sleep physiology. Front. Neurol. 2012, 3, 48. [CrossRef]

34. Kubitz, K.A.; Landers, D.M.; Petruzzello, S.J.; Han, M. The effects of acute and chronic exercise on sleep. A meta-analytic review. Sports Med. 1996, 21, 277-291. [CrossRef]

35. Reynolds, G.O.; Otto, M.W.; Ellis, T.D.; Cronin-Golomb, A. The Therapeutic Potential of Exercise to Improve Mood, Cognition, and Sleep in Parkinson's Disease. Mov. Disord. 2016, 31, 23-38. [CrossRef] [PubMed] 
36. Amara, A.W.; Memon, A.A. Effects of Exercise on Non-motor Symptoms in Parkinson's Disease. Clin. Ther. 2018, 40, 8-15. [CrossRef] [PubMed]

37. Cusso, M.E.; Donald, K.J.; Khoo, T.K. The Impact of Physical Activity on Non-Motor Symptoms in Parkinson's Disease: A Systematic Review. Front. Med. 2016, 3, 35. [CrossRef]

38. Memon, A.A.; Coleman, J.J.; Amara, A.W. Effects of exercise on sleep in neurodegenerative disease. Neurobiol. Dis. 2020, 140, 104859. [CrossRef] [PubMed]

39. Moher, D.; Liberati, A.; Tetzlaff, J.; Altman, D.G. PRISMA Group. Preferred reporting items for systematic reviews and meta-analyses: The PRISMA statement. BMJ 2009, 339, b2535. [CrossRef]

40. Higgins, J.P.T.; Thomas, J.; Chandler, J.; Cumpston, M.; Li, T.; Page, M.J.; Welch, V.A. Cochrane Handbook for Systematic Reviews of Interventions Version 6.2. Cochrane 2020. Available online: www.training.cochrane.org/handbook (accessed on 1 February 2021).

41. Singh, A.; Danda, D.; Hussain, S.; Najmi, A.K.; Mathew, A.; Goel, R.; Lakhan, S.E.; Tajudheen, B.; Antony, B. Efficacy and safety of tocilizumab in treatment of Takayasu arteritis: A systematic review of randomized controlled trials. Mod. Rheumatol. 2021, 31, 197-204. [CrossRef]

42. Tramontano, M.; Russo, V.; Spitoni, G.F.; Ciancarelli, I.; Paolucci, S.; Manzari, L.; Morone, G. Efficacy of Vestibular Rehabilitation in Patients With Neurologic Disorders: A Systematic Review. Arch. Phys. Med. Rehabil. 2021, 102, 1379-1389. [CrossRef]

43. Fulk, G.; Duncan, P.; Klingman, K.J. Sleep problems worsen health-related quality of life and participation during the first 12 months of stroke rehabilitation. Clin. Rehabil. 2020, 34, 1400-1408. [CrossRef] [PubMed]

44. Amara, A.W.; Wood, K.H.; Joop, A.; Memon, R.A.; Pilkington, J.; Tuggle, S.C.; Reams, J.; Barrett, M.J.; Edwards, D.A.; Weltman, A.L.; et al. Randomized, Controlled Trial of Exercise on Objective and Subjective Sleep in Parkinson's Disease. Mov. Disord. 2020, 35, 947-958. [CrossRef] [PubMed]

45. Al-Sharman, A.; Khalil, H.; El-Salem, K.; Aldughmi, M.; Aburub, A. The effects of aerobic exercise on sleep quality measures and sleep-related biomarkers in individuals with Multiple Sclerosis: A pilot randomised controlled trial. NeuroRehabilitation 2019, 45, 107-115. [CrossRef]

46. Sadeghi Bahmani, D.; Razazian, N.; Farnia, V.; Alikhani, M.; Tatari, F.; Brand, S. Compared to an active control condition, in persons with multiple sclerosis two different types of exercise training improved sleep and depression, but not fatigue, paresthesia, and intolerance of uncertainty. Mult. Scler. Relat. Disord. 2019, 36, 101356. [CrossRef]

47. Silva-Batista, C.; de Brito, L.C.; Corcos, D.M.; Roschel, H.; de Mello, M.T.; Piemonte, M.E.P.; Tricoli, V.; Ugrinowitsch, C. Resistance Training Improves Sleep Quality in Subjects With Moderate Parkinson's Disease. J. Strength Cond. Res. 2017, 31, $2270-2277$. [CrossRef] [PubMed]

48. Wang, W.; Sawada, M.; Noriyama, Y.; Arita, K.; Ota, T.; Sadamatsu, M.; Kiyotou, R.; Hirai, M.; Kishimoto, T. Tai Chi exercise versus rehabilitation for the elderly with cerebral vascular disorder: A single-blinded randomized controlled trial. Psychogeriatrics 2010, 10, 160-166. [CrossRef] [PubMed]

49. Nascimento, C.M.; Ayan, C.; Cancela, J.M.; Gobbi, L.T.; Gobbi, S.; Stella, F. Effect of a multimodal exercise program on sleep disturbances and instrumental activities of daily living performance on Parkinson's and Alzheimer's disease patients. Geriatr. Gerontol. Int. 2014, 14, 259-266. [CrossRef] [PubMed]

50. De Mello, M.T.; Silva, A.C.; Esteves, A.M.; Tufik, S. Reduction of periodic leg movement in individuals with paraplegia following aerobic physical exercise. Spinal Cord 2002, 40, 646-649. [CrossRef]

51. Colledge, F.; Brand, S.; Pühse, U.; Holsboer-Trachsler, E.; Zimmerer, S.; Schleith, R.; Gerber, M. A Twelve-Week Moderate Exercise Programme Improved Symptoms of Depression, Insomnia, and Verbal Learning in Post-Aneurysmal Subarachnoid Haemorrhage Patients: A Comparison with Meningioma Patients and Healthy Controls. Neuropsychobiology 2017, 76, 59-71. [CrossRef]

52. Tidman, M.; Skotzke, E. Effects of a community-based exercise program on mobility, balance, cognition, sleep, activities of daily living, and quality of life in PD: A pilot study. Neurodegener. Dis. Manag. 2020, 10, 27-39. [CrossRef] [PubMed]

53. Castelnuovo, G.; Giusti, E.M.; Manzoni, G.M.; Saviola, D.; Gabrielli, S.; Lacerenza, M.; Pietrabissa, G.; Cattivelli, R.; Spatola, C.A.M.; Rossi, A.; et al. What Is the Role of the Placebo Effect for Pain Relief in Neurorehabilitation? Clinical Implications From the Italian Consensus Conference on Pain in Neurorehabilitation. Front. Neurol. 2018, 9, 310. [CrossRef] [PubMed]

54. Bargiotas, P.; Lachenmayerm, M.L.; Schreier, D.R.; Mathis, J.; Bassetti, C.L. Sleepiness and sleepiness perception in patients with Parkinson's disease: A clinical and electrophysiological study. Sleep 2019, 42, zsz004. [CrossRef] [PubMed]

55. Morone, G.; Paolucci, S.; Mattia, D.; Pichiorri, F.; Tramontano, M.; Iosa, M. The 3Ts of the new millennium neurorehabilitation gym: Therapy, technology, translationality. Expert Rev. Med. Dev. 2016, 13, 785-787. [CrossRef] 